\title{
ENZYME REGULATION DURING DEVELOPMENT AND AGING
}

\author{
Chung Wu \\ Departments of Biological Chemistry and Internal Medicine \\ The University of Michigan Medical School \\ Ann Arbor, Michigan 48109
}

Received February 21,1977

\section{Summary}

Glutamine synthetase and ornithine aminotransferase activities have been shown to decrease in aging rats, but the decline varies in degree for the two enzymes in liver and kidney. The responsiveness of the two liver enzymes to glucagon and cyclic AMP demonstrates a similarity in enzyme regulation between developing and aging rats and a contrast in enzyme regulation between these animals and young adults. The results are interpreted as showing a reversion in certain aspects of enzyme regulation during aging to those prevailing in the perinatal state.

\section{Introduction}

Earlier studies on decrease in enzyme activities associated with aging have been made with mammalian erythrocytes because of their ease of fractionation into different age groups. Most of these studies involved enzymes of carbohydrate metabolism (1-3) . However, changes accompanying aging of one kind of cells may not represent the derangement arising from aging of an organism. Recently, enzymes in other metabolic pathways have received attention and a decline of their activities in aging mammals has consistently been observed (4-8). One enzyme that has been studied in some detail in connection with aging is aldolase. Gershon and Gershon (9) reported a decline of liver aldolase activity in aged mice and showed that the decline resulted from formation of inactive enzyme molecules.

Comparison of basal enzyme activities in tissues of animals representing two physiologically different states may not reveal the potentiality of the enzymes to respond when challenged by a stress. For instance, many rat hepatomas had basal glutamine synthetase activity similar to that of normal liver, but the response of the enzyme in the hepatomas to hormonal and nutritional stress was quite different from that in normal liver (10). Hence, it would be informative to study not only the change in the basal activities of enzymes during 
aging, but also the capability of the enzymes to respond to a given metabolic stimulus. In this communication, we report our observations on two enzymes in amino acid metabolism. glutamine synthetase (EC 6.3.1.2) and ornithine aminotransferase (EC 2,6.1.13).

\section{Materials and Methods}

Animals-- Rats of the Sprague-Dawley and Fischer 344 strains were used. Sprague-Dawley rats were obtained from Spartan, Inc. (Haslett, Mich.); Fischer rats, from Charles River Labs. (Wilmington, Mass.) through the National Institute on Aging.

Hormonal administration-- Glucagon (Eli Lilly, ampoules) and cyclic AMP (Sigma Chemical Co., dissolved in $0.9 \% \mathrm{NaCl}$ and adjusted to $\mathrm{pH} 7.4$ ) were injected subcutaneously at 1.5 and $50 \mu \mathrm{g}$, respectively, per g body weight at 12$\mathrm{hr}$ intervals for $24 \mathrm{hr}$, the last injection being $12 \mathrm{hr}$ before enzyme assay.

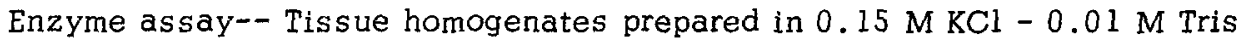
buffer, pH 7.0, were used for enzyme assays. Glutamine synthetase activity was assayed as before (11), but with the addition of an ATP-regenerating system (12). The enzyme activity is expressed as $\mu$ moles of $\gamma$-glutamylhydroxamate formed/ $\mathrm{g}$ tissue/ $\mathrm{hr}$. Ornithine aminotransferase activity was assayed according to Herzfeld and Knox (13). The enzyme activity is expressed as umoles of glutamate $\gamma$-semialdehyde formed/g tissue/ $\mathrm{hr}$.

Protein determination-- The procedure of Lowry et al. (14) was used with hovine serum albumin as the standard.

\section{Results}

In the two tissues we used, liver and kidney, the protein concentration showed variations with age. Thus, in the three groups of $3-, 16-$, and 28-month old male Fischer rats, the liver protein values were $193 \pm 14,242 \pm 29$, and $181 \pm 12 \mathrm{mg} / \mathrm{g}$ liver, respectively, and the kidney protein values were $201 \pm 15$, $193 \pm 17$, and $149 \pm 8 \mathrm{mg} / \mathrm{g}$ kidney, respectively. Hence, the protein concentrations in both liver and kidney of 28 -month old rats were lower than those of 16 -month old rats.

Liver glutamine synthetase activity showed a definite decline with age in both strains of the rat. Table 1 summarizes the findings. The activity in 14and 16 -month old rats had decreased to about $53 \%$ of that in 3 -month old rats . Possibly, the loss in activity had begun some time before the animals were 14 months old. The enzyme activity continued to decline so that in 28 -month old rats it was only $32 \%$ of that in young adults. However, the kidney enzyme did not show any significant lowering until the animals had attained old age. The life span of the rat is about 3 years. Hence, 28 months in the rat may be considered as equivalent to 70 years of human life.

Liver ornithine aminotransferase activity appeared to be less affected by 
Table 1. Decline of glutamine synthetase and ornithine aminotransferase activities in liver and kidney of aging male rats

\begin{tabular}{lllllc}
\hline \multirow{2}{*}{$\begin{array}{c}\text { Age of rats } \\
\text { (strain) }\end{array}$} & \multicolumn{2}{c}{ Synthetase activity } & \multicolumn{2}{c}{ Aminotransferase activity } \\
\cline { 2 - 6 } & Liver & Kidney & Liver & Kidney \\
\hline 3 months (S-D) & $260 \pm 28^{\beta}$ & $86.5 \pm 3.1$ & $123 \pm 17$ & $187 \pm 25$ \\
14 months (S-D) & $138 \pm 33$ & $63.0 \pm 16.0$ & $124 \pm 31$ & $126 \pm 19$ \\
3 months (F) & $339 \pm 47$ & $69.9 \pm 9.1$ & 102 & \pm 10 & $175 \pm 45$ \\
16 months (F) & $179 \pm 23$ & $63.8 \pm 6.5$ & $91.5 \pm 20.6$ & $172 \pm 13$ \\
28 months (F) & $110 \pm 17$ & $38.4 \pm 6.2$ & $67.5 \pm 6.9$ & $186 \pm 26$ \\
\hline
\end{tabular}

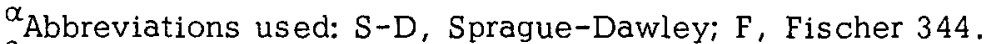

${ }^{\beta}$ Standard deviation.

aging than liver glutamine synthetase activity. The enzyme activity remained unchanged throughout most of the life of the rat and showed only a $34 \%$ decrease at 28 months of age. On the other hand, kidney ornithine aminotransferase activity was not affected at all by aging. In fact, the specific activity increased since the protein concentration decreased in aged rats as noted above.

In order to be certain that lower activities observed in aging rat tissues were not due to rapid deterioration of the enzymes in vitro, we assayed the enzyme activities again in the homogenates after being kept at $4^{\circ}$ for 24 hours. Compared with the activities in fresh homogenates, glutamine synthetase activity declined 12 and $17 \%$ in 24 hours in liver homogenates of 3 - and 28 -month old rats, respectively, while ornithine aminotransferase activity decreased 22 and $24 \%$ in kidney homogenates of the same animals. Hence, the two enzymes from aged rats were as stable in vitro as those from younger rats.

Determination of the basal activity of an enzyme often does not reveal the potentiality of the enzyme to respond to a given stimulus when challenged. Therefore, we did experiments to determine the responsiveness of the two liver enzymes to metabolic modulations. Moreover, we wanted to compare the responses seen in aging and developing rats with those seen in young adults, which we used as a frame of reference. 
Table 2. Non-responsiveness of liver glutamine synthetase in neonatal and aged male rats to glucagon

\begin{tabular}{lcccc}
\hline \multirow{2}{*}{$\begin{array}{c}\text { Age of rats } \\
\text { (strain) }\end{array}$} & \multicolumn{4}{c}{ Synthetase activity } \\
\cline { 2 - 5 } & Control & Glucagon & \% Change \\
\hline 10 days $^{\alpha}$ (S-D) & $75.0 \pm 2.2$ & $77.2 \pm 3.4$ & +2.9 \\
3 months (S-D) & $269 \pm 30$ & $199 \quad \pm 8$ & -26.0 \\
3 months (F) & $339 \pm 47$ & $229 \quad \pm 29$ & -32.4 \\
28 months (F) & $106 \pm 15$ & $114 \quad \pm 22$ & +7.5 \\
\hline
\end{tabular}

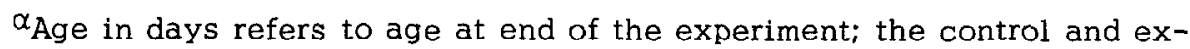
perimental groups were litter mates of both sexes.

Table 2 shows the response of liver glutamine synthetase to glucagon in neonatal, young adult, and aged rats. We can see that the hormone lowered the enzyme activity in young adults by about $30 \%$, but it had no effect on the enzyme activity in either neonatal or aged rats. Apparently, the aged rat has assumed a mode of regulating glutamine synthetase by departing from that found in the young adult rat and returning to that observed in the developing rat. Continued injections of glucagon for 3 days lowered the liver enzyme activity further, although the enzyme activity in kidney, brain, and testis was not appreciably affected by the hormone (12). Addition of glucagon to the reaction mixture did not affect the enzyme activity, nor did injection of cyclic AMP evoke the glucagon effect. The mechanism underlying this effect deserves further study.

We also investigated the effect of cyclic AMP administration on liver ornithine aminotransferase. Table 3 presents the results. The developmental formation of this liver enzyme shows a drastic decline in activity on the 10th day of life. Herzfeld and Greengard (15) have observed a similar decline in the enzyme activity with a somewhat different magnitude on the 8th day of life of the rat. We can see that, between the age of 5 and 15 days, cyclic AMP raised liver ornithine aminotransferase 50-100\% above the control levels. By the time the animals were 20 days old, however, the enzyme was unresponsive to the cyclic nucleotide, as was the enzyme in young adult rats. Furthermore, as the animals grew older, the neonatal pattern of regulation reemerged so that liver ornithine 
Table 3. Over-responsiveness of liver ornithine aminotransferase in neonatal and aging female rats to cyclic AMP

\begin{tabular}{lrccc}
\hline \multirow{2}{*}{ Age of rats $\alpha$} & \multicolumn{4}{c}{ Aminotransferase activity } \\
\cline { 2 - 5 } & Control & Cyclic AMP & $\%$ Change \\
\hline 5 days & $16.5 \pm 0.4$ & $23.8 \pm 1.0$ & +44.2 \\
10 days & $6.6 \pm 1.1$ & $13.3 \pm 1.1$ & +102 \\
15 days & $26.2 \pm 2.5$ & $40.4 \pm 3.9$ & +58.9 \\
20 days & $78.4 \pm 4.4$ & $84.3 \pm 3.2$ & +7.5 \\
3 months & $289 \pm 17$ & $300 \pm 34$ & +3.8 \\
16 months & $177 \pm 34$ & $354 \pm 35$ & +100 \\
\hline
\end{tabular}

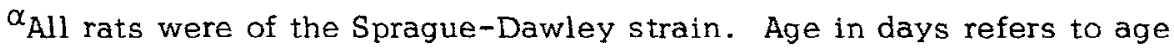
at end of the experiment. Each age group of neonatal rats was from a separate litter, but the control and treated rats of the same age were litter mates of both sexes.

aminotransferase became fully responsive to cyclic AMP again in 16-month old rats.

\section{Discussion}

The results presented herein show that the two enzymes, glutamine synthetase and ornithine aminotransferase, followed two patterns of decline in liver of aging rats. On the one hand, glutamine synthetase activity already showed a significant decline when the animals were 14 months old and the decrease intensified with advancing age. On the other hand, ornithine aminotransferase activity did not show a significant decline until the animals reached 28 months of age. Moreover, for the same enzyme, the magnitude of decrease was greater in liver than in kidney. For this reason, ornithine aminotransferase activity in kidney showed no discernible decline with age. We are currently studying the mech anism responsible for the decrease in these two enzymes in aging rats.

In the present study, we have observed that the competence of aging animals to respond to, or to accommodate, a given stimulus also shows deviation from that of young adults. Thus, the response of the two enzymes to glucagon and cyclic AMP in aging rats is different from that in young adults, but is simi- 
lar to that in neonatal rats. If ontogenic development involves programmed elaboration of its biochemical control machinery through enzymic differentiation (16), then aging would represent an accumulation of multiple failures by the organism to maintain this differentiation. Apparently, the aging phenomenon can be looked upon as an altered enzyme regulation. In a way, the aging organis $m$ does not develop a new regulatory mechanism, but repossesses what it once used in the neonatal state. We consider this shift in enzyme regulation during aging from that prevalent in the early adulthood to that operative in the neonatal state as a step backward, since the aging organism has lost its ability to maintain a more elaborate metabolic control machinery in exchange for a less elaborate regulatory apparatus. This reversion or return to the infantile regulation triggers aging. Accordingly, rejuvenation may be considered a process in which such a reversion has been prevented or postponed.

Earlier, we proposed a reversion hypothesis to explain the apparent coincidence in enzyme regulation between perinatal and neoplastic tissues and the apparent contrast in enzyme regulation between adult and neoplastic tissues (17, 18). Admittedly, the proposed scheme is simplistic, but the central idea behind it has been consistent with experimental findings. More recently, this concept has received support from a study of isozyme patterns in rat hepatomas by Weinhouse (19), who reported that normal adult pattern of a number of liver isozymes "is reversed" to the primordial isozyme pattern in hepatomas. In the present study, we have shown a similar phenomenon of reversion of enzyme regulation in aging rats to that in developing rats. Perhaps, the physiological process of aging and the pathological state of neoplasia adopt certain altered mechanisms common to both of them.

\section{References}

1. Brewer, G. J. and Powell, R. D. (1963) Nature, 199, 704-705.

2. Piomelli, S., Corash, L. M. , Davenport, D. D., Miraglia, J. and Amorosi, E. L. (1968) J. Clin. Invest., 47, 940-948.

3. Fornaini, G., Leoncini, G., Segni, P., Calabria, G. A. and Dacha, M. (1969) Eur. J. Biochem., 7, 214-222.

4. Fonda, M. L., Acree, D. W. and Auerbach, S. B. (1973) Arch, Biochem. Biophys. . 159, 622-628.

5. Barton, R. W., Waters, L. C. and Yang, W. K. (1974) Federation Proc., $33,1419$.

6. Yip, L. C., Dancis, J., Mathieson, B. and Balis, M. E. (1974) Biochemistry, $13,2558-2561$.

7. Story, J. A., Tepper, S. A. and Kritchevsky, D. (1975) Federation Proc., $34,277$. 
8. Layman, D. K., Ricca, G. A. and Richardson, A. (1976) Arch. Biochem. Biophys., 173, 246-254.

9. Gershon, H. and Gershon, D. (1973) Proc. Nat. Acad. Sci. (U.S.A.), 70, 909-913.

10. Wu, C. and Morris, H. P. (1970) Cancer Res., 30, 2675-2684.

11. Wu, C. (1964) Arch. Biochem. Biophys., 106, 402-409.

12. Wu, C. (1976) In: Control Mechanisms in Cancer, Criss, W. E., Ono, T. and Sabine, J. R. (eds.), pp. 125-138, Raven Press, New York.

13. Herzfeld, A. and Knox, W. E. (1968) J. Biol. Chem., 243, 3327-3332.

14. Lowry, O. H., Rosebrough, N. J., Farr, A. L. and Randall, R. J. (1951) J. Biol. Chem., 193, 265-275.

15. Herzfeld, A, and Greengard, O. (1969) J. Biol. Chem., 244, 4894-4898.

16. Greengard, O. (1970) In: Biochemical Actions of Hormones, Litwack, G. (ed.), I, pp. 53-87, Academic Press, New York.

17. Wu, C. (1973) Int. J. Cancer, 11, 438-447.

18. Wu, C. (1973) Bot. Bull. Academia Sinica, 14, 115-124.

19. Weinhouse, S. (1976) Cancer Res., 36, 4330-4331. 